\title{
A novel electrochemical aptamer-antibody sandwich assay for lysozyme detection
}

Cristina Ocaña $^{\mathrm{a}, \mathrm{b}}$, AkhtarHayat $^{\mathrm{b}, \mathrm{c}}$, RupeshMishra ${ }^{\mathrm{b}}$, Alina Vasilescu ${ }^{\mathrm{d}}$, Manel del Valle ${ }^{\mathrm{a}}$, Jean-Louis Marty ${ }^{b^{*}}$

${ }^{a}$ Sensors and Biosensors Group, Department of Chemistry, UniversitatAutònoma de Barcelona, 08193 Bellaterra, Spain

${ }^{b}$ Université de Perpignan, Laboratoire IMAGES, EA 4218, 52 avenue Paul Alduy, bât. $S$, Perpignan cedex 66860, France

${ }^{c}$ Interdisciplinary Research Centre in Biomedical Materials (IRCBM), COMSATS Institute of Information Technology (CIIT), Lahore, Pakistan

${ }^{d}$ International Centre of Biodynamics, 1B IntrareaPortocalelor, sector 6, 060101, Bucharest, Romania

*Corresponding author: jlmarty@univ-perp.fr

\begin{abstract}
In this paper, we reported a novel electrochemical aptamer-antibody based sandwich biosensor for the detection of lysozyme. In the sensing strategy, Anti-lysozyme aptamer was immobilized onto the carbon electrode surface by covalent binding via diazonium salt chemistry. After incubating with the target protein (lysozyme), a biotinylated antibody was used to complete the sandwich format. The subsequent additions of avidin-alkaline phosphatase as enzyme label, and 1-napthyl phosphate substrate (1-NPP) allowed to determine the concentration of lysozyme (Lys) via Differential Pulse Voltammetry (DPV) of the generated enzyme reaction product, 1napthol. Using this strategy, a wide detection range from $1 \mathrm{fM}$ to $5 \mathrm{nM}$ was obtained for target lysozyme, with a detection limit of 4.3fM. The control experiments were also carried out by using albumin (BSA), cytochrome $\mathrm{c}$ and casein. The results showed that the proposed biosensor had good specificity, stability and reproducibility for lysozyme analysis. In addition, the biosensor was applied for detecting lysozyme in spiked wine samples, very good recovery rates were obtained in the range from 96.67 to $102 \%$ for lysozyme detection. This implies that the proposed sandwich biosensor is a promising analytical tool for the analysis of lysozyme in real samples.
\end{abstract}

Keywords: aptamer-antibody sandwich, biosensor, lysozyme detection, differential pulse voltammetry, wine sample

Post-print of: Ocaña, C. et al "A novel electrochemical aptamer-antibody sandwich assay for lysozyme detection" in The analyst (Ed. RSC), vol. 140, issue 12 (June 2015), p. 4148-4153. The final version is available at: DOI 10.1039/c5an00243e 


\section{Introduction}

Nowadays, use of biosensors for detection and quantification of proteins plays a vital role in research ${ }^{1}$, clinical applications ${ }^{2}$ and food industry ${ }^{3}$. Biosensors are analytical devices which incorporate a biomolecule to provide specific recognition for an analyte together with transduction technology to detect and quantify the binding taking place between analyte and detector molecule ${ }^{4}$. Traditionally, enzymes, antibodies and proteins have been employed in biosensors as biorecognition species. Since their discovery in $1990^{5}$, aptamers have attracted considerable attention in biosensor development ${ }^{6}$. Aptamers are artificial DNA or RNA oligonucleotides selected in vitro which have the ability to bind to proteins, small molecules or even whole cells, with high affinity and specificity ${ }^{7}$. They offer many advantages over antibodies such as relatively easy production, highly affinity and specificity, easy chemical modification and high stability ${ }^{8}$. Thanks to these excellent properties, a number of aptamer-based sensors have been developed using different transducer techniques ${ }^{9,10}$. Among different types of biosensors, electrochemical biosensing is of particular interest due to its remarkable sensitivity, simple instrumentation, fast response, low cost and portability ${ }^{11}$.

Lysozyme (Lys) is a relatively small protein $(14.3 \mathrm{kDa})$ consisting of only 129 amino acid residues, and is widely distributed in the nature ${ }^{12}$. It has an isoelectric point of 11.0 and constitutes $3.5 \%$ of egg white protein. It is clear that lysozyme's relatively small size and simplicity makes it an excellent model analyte for novel methods in protein detection. This protein is also known as $\mathrm{N}$-acetylmuramide glycan hydrolase due to its property to destroy bacterial cellular membranes by catalyzing the hydrolysis of glycosidic bonds between $\mathrm{N}$-acetylmuramic acid and $\mathrm{N}$-acetylglucosaminein peptidoglycan residues of Gram-positive bacteria cell walls ${ }^{13}$. Moreover, the monitoring of lysozyme level is used as a marker of some health problems such as 
bronchopulmonary dysplasia in newborns ${ }^{14}$, conjunctivitis, kidney problems ${ }^{15}$ and leukemia ${ }^{16}$. Additionally, Lys has been widely used as an antimicrobial agent in the production of wine ${ }^{17}$, cheese ${ }^{18}$, beers ${ }^{19}$ and as well as to prolong the shelf-life of shrimp, surimi products and sausages ${ }^{20}$. Specifically, in wine-making, Lys has been used since 1990 to prevent or mitigate heterolactic fermentation ${ }^{17}$. The maximum permitted level of lysozyme in wine samples is $500 \mathrm{mg} / \mathrm{L}(\sim 35 \mu \mathrm{M})^{21}$. Being an egg-protein, lysozyme is considered as an allergen; therefore developing new, rapid, cheap and sensitive methods for the detection of Lys is of great significance.

Presently, the available analytical methods for the detection of lysozyme include conventional methods like chromatographic or immunosensing techniques based on ELISA, which have high sensitivity, but high cost and experimental complexity. Thus, numerous sensors have been presented as alternatives to overcome these limitations based on mainly electrochemical and optical detection ${ }^{22}$. In this work, we report a novel electrochemical aptamer-antibody sandwich assay for the detection of Lys. Differential Pulse Voltammetry (DPV) technique was used to detect Lys via 1-naphtol oxidation signal changes. For this purpose, the aptamer was immobilized onto the electrode surface by covalent binding via diazonium salt. After incubating with lysozyme, a biotinylated antibody was used to form the sandwich format. The addition of avidin modified alkaline phosphatase and the 1-NPP enzymatic substrate allowed to detect lysozyme based on the electrochemical oxidation signals of 1-naphtol. Results showed that this novel biosensor can be used for accurate quantification of the concentration of Lys in spiked wine samples. The developed biosensor is simple, sensitive, specific and fast for the detection of Lys.

\section{Experimental}

\subsection{Chemicals and materials}


Potassium dihydrogen phosphate, sodium monophosphate, bovine serum alumina (BSA), lysozyme (Lys), avidin-labeled alkaline phosphatase (Av-ALP), casein, biotinlabeled rabbit anti-chicken Lys antibody (AbLysBio), magnesium chloride, potassium chloride, sodium chloride, ethanolamine, diethanolamine (DEA), Nhydroxysuccinimide (NHS), N-(3-dimethylaminopropyle)-N'-ethyle-carbodiimide hydrochloride (EDC), 4-aminobenzoic acid (ABA), 1-naphtyl phosphate (1-NP) and sodium nitrite were purchased from Sigma (St. Louis, MO, USA). All reagents were analytical reagent grade. The aptamer used was:

$$
\operatorname{AptLys~}^{23}
$$

5'-NH${ }_{2}$-GCA GCT AAG CAG GCG GCT CAC AAA ACC ATT CGC ATG CGG C-3' and was provided by Eurogenetic (France)

All solutions were made up using MilliQ water. The buffers employed were: binding buffer (BB) $\quad\left(1 \mathrm{mM} \quad \mathrm{MgCL}_{2}, \quad 2.7 \mathrm{mMKCl}, \quad 140 \mathrm{mMNaCl}, \quad 0.1 \mathrm{mM} \quad \mathrm{Na}_{2} \mathrm{HPO}_{4}\right.$ and $\left.1.8 \mathrm{mMKH}_{2} \mathrm{PO}_{4} \mathrm{pH} 7.4\right), 10 \%$ DEA buffer ( $\mathrm{pH} 9.5$ ) and 100mM MES buffer containing $0.09 \% \mathrm{NaCl}$.

\subsection{Equipment}

The electrochemical measurements were performed using an Autolab PGSTAT100 potentiostat/galvanostat (Eco Chimie, Netherlands) controlled by General Purpose Electrochemical System software (GPES) (4.9) for voltammetry. Screen printed carbon electrodes (SPCEs) were fabricated using a DEK 248 screen-printing system. The SPCE consists of conventional three electrode configuration with graphite as working (4-mm diameter disk $)$ and counter $(16 \mathrm{~mm} \times 1.5 \mathrm{~mm}$ curved line $)$ electrode, and $\mathrm{Ag} / \mathrm{AgCl}(16$ $\mathrm{mm} \times 1.5 \mathrm{~mm}$ straight line) as pseudo reference electrode.

\subsection{Experimental protocol}




\subsubsection{Electrochemical SPE pretreatment}

SPE was subjected to electrochemical pretreatment by 10 cyclic potential scans between 1.0 and $-1.5 \mathrm{~V}$ at scan rate of $0.2 \mathrm{~V} / \mathrm{s}$ in $0.5 \mathrm{M} \mathrm{H}_{2} \mathrm{SO}_{4}$ and $0.1 \mathrm{M} \mathrm{KCl}$. Then, the electrodes were rinsed with water.

\subsubsection{Immobilization of AptLys onto the electrode surface}

In detail, the diazonium cation was synthesized by in situ reaction of $2 \mu \mathrm{L}$ of $1 \mathrm{M}$ $\mathrm{NaNO}_{2}$ and $1 \mathrm{~mL}$ of $2 \mathrm{mM}$ ABA prepared in $0.5 \mathrm{M} \mathrm{HCl}$. The mixture was left to react for $5 \mathrm{~min}$ at room temperature. $100 \mu \mathrm{L}$ of this mixture and $100 \mu \mathrm{L}$ of $0.5 \mathrm{M} \mathrm{HCl}$ were deposited onto the electrode surface and the electrochemical modification was performed by linear sweep voltammetry from 0.6 to $-0.8 \mathrm{~V}$. After modification, the electrode was rinsed three times with distilled water. The carboxylic groups onto the electrode surface were activated with $100 \mu \mathrm{L}$ of $100 \mathrm{mM}$ EDC and $25 \mathrm{mM}$ NHS in $100 \mathrm{mM}$ MES buffer for 1 hour. After rinsing three times with distilled water, $30 \mu \mathrm{L}$ of $10 \mu \mathrm{M}$ solution of Apt were incubated onto the electrode surface for 1 hour. After that, the electrodes were washed three times with $\mathrm{BB}$ to remove the unbound aptamer. In order to deactivate the remaining succinimide groups, the electrodes were incubated with $30 \mu \mathrm{L}$ of $1 \mathrm{M}$ ethanolamine solution. After washing three times with $\mathrm{BB}$, the electrodes were incubated with $30 \mu \mathrm{L}$ of $5 \%$ BSA solution for 1 h to avoid nonspecific adsorption. The modified electrodes can be used directly or stored dry at $4^{\circ} \mathrm{C}$ for several days without decrease in the sensitivity.

\subsubsection{Aptamer-antibody sandwich assay}

The electrodes were incubated with different concentrations of Lys for $15 \mathrm{~min}$. Then, the electrodes were washed three times with BB.In order to achieve the aptamerantibody sandwich, the electrodes were incubated with $30 \mu \mathrm{L}$ of anti-Lys antibody from a 1/1500 dilution of the stock solution in BB buffer. The incubation took place for $1 \mathrm{~h}$. 
This was followed by three washing steps using BB. Then, $30 \mu \mathrm{L}$ of av-ALP, from $1 / 12500$ dilution from the stock solution of enzyme, were deposited on the electrodes for $1 \mathrm{~h}$. After that, the electrodes were washed three times with BB.

\subsubsection{Electrochemical detection}

$90 \mu \mathrm{L}$ of $10 \%$ DEA buffer and $10 \mu \mathrm{L}$ of $1-\mathrm{NPP} 5 \mathrm{mg} \cdot \mathrm{mL}^{-1}$ were added on the electrode surface and incubated for $2 \mathrm{~min}$ at room temperature. Electrochemical detection was performed by DPV. A modulation time of $2 \mathrm{~s}$, interval time of $0.2 \mathrm{~s}$, initial potential of $0.1 \mathrm{~V}$, end potential of $0.4 \mathrm{~V}$, step potential of $0.01 \mathrm{~V}$, modulation amplitude of $0.06 \mathrm{~V}$ and stand- by potential of $0 \mathrm{~V}$ were applied.The height of the resulting oxidation peak was recorded and plotted against Lys concentration to give a calibration curve.

\subsubsection{Wine samples preparation}

Wine samples were prepared following a protocol from a previous study ${ }^{24}$. Briefly, 1 $\mathrm{mL}$ of wine sample was spiked with $200 \mu \mathrm{M}$ of Lys and allowed to stand for $3 \mathrm{~min}$. Next, $200 \mu \mathrm{L}$ of a $5 \mathrm{M} \mathrm{NaCl}$ solution containing $5 \%$ Tween-20 surfactant were added to $200 \mu \mathrm{L}$ of lysozyme-wine mixture and diluted to a final volume of $1 \mathrm{~mL}$ using $20 \mathrm{mM}$ MES buffer $\mathrm{pH} 6$ with $1 \mathrm{mM} \mathrm{MgCl}_{2}$. This mixture was further centrifuged at 5000rpm for $5 \mathrm{~min}$ and diluted using the buffer aforesaid to obtain the desired concentration of Lys.

\section{Results and discussion}

\subsection{Principle of the aptamer-antibody sandwich assay}

Figure 1 illustrates the different steps involved in the fabrication of biosensor for the detection of Lys based on its specific recognition by aptamer-antibody assay. As described in Section 2.3, the aptamer was covalently immobilized through EDC/NHS chemistry via diazonium salt on the SPE surface. This step was followed by a blocking step with BSA to avoid non-specific adsorption on the transducer surface. Then, Anti- 


\section{Analyst}

Lys antibody was incubated on the sensing platform to obtain sandwich type detection. Thereafter, a solution of avidin modified-ALP was deposited onto the electrode surface to achieve coupling to the antibody through biotin-avidin affinity. Finally, the biosensor was immersed in DEA buffer solution of $\mathrm{pH} 9.5$ containing 1-NPP as ALP substrate, and Lys was determined by differential pulse voltammetry of the generated 1-naphtol as the enzyme reaction product.

$<$ Figure 1 $>$

\subsection{Optimization of the working experimental conditions}

In order to achieve the improved analytical characteristics of a proposed biosensor, it is of vital importance to optimize the different experimental parameters. In this context, several parameters including concentrations of anti-Lys antibody and avidin modified enzyme, and their incubation time with Lys were optimized prior to perform concentration dependence response of the proposed sandwich assay. Figure $2 \mathrm{a}$ shows the voltammetric peak response of $1-N P P$ in the presence of different concentrations of Anti-Lys antibody (1/3000 from to $1 / 500$, dilutions from stock solution of antibody). As can be observed, the current response increased rapidly with increasing concentration of Anti-Lys antibody, with a maximal electrochemical output signal at 1/1500. Similarly, Figure $2 \mathrm{~b}$ shows that peak current increased with increasing concentration of avidin modified ALP till 1/12500 (dilution from stock enzyme solution), which was followed by a decrease in response for subsequent increasing concentration, indicating the saturation point of enzyme label is reached. Thus, 1/1500 and1/12500 were chosen as the optimal dilutions for Anti-Lys antibody and avidin modified-ALP respectively.

The effect of the incubation time of Lys on the current response of the biosensor was also studied. As can be seen from Figure $2 \mathrm{c}$, the maximum peak current of 1-NPP 


\section{Analyst}

was observed for an incubation period of $15 \mathrm{~min}$. For longer incubation times, the peak current was decreased. Thus, according to the experimental results, an incubation time period of 15 min was selected to perform the further experiments.

$<$ Figure 2>

\subsection{Analytical performance of the aptamer-antibody sandwich biosensor}

In order to perform the quantitative analysis, the designed biosensor was incubated with different concentrations of Lys under the optimal conditions, and the DPV responses were recorded to draw a calibration curve. As shown in the Figure 3a, the oxidation peak current increased with the increasing concentration of Lys. The peak current was plotted against the concentration of Lys, and the calibration plots (Figure 3b) exhibited a good linear correlation between the peak current and the logarithm of Lys concentrations in the range from $5 \mathrm{fM}$ to $5 \mathrm{nM}$ with a correlation coefficient of 0.998 . The calculated limit of detection (LOD) for Lys was 4.3fM. The reproducibility of the method showed a relative standard deviation (RSD) of 5.5\%, obtained from a series of 3 experiments carried out in a concentration of $5 \mathrm{nM}$ of Lys. Table 1 provides a comparison of different biosensors reported in the literature for Lys detection. The data in Table 1 indicates the lowest limit of detection of our proposed sandwich biosensor as compared to the LOD of previously reported biosensors for Lys detection. In addition, the linear range was greatly improved, being much wider than for other biosensors.

$<$ Figure 3 $>$

$<$ Table 1>

\subsection{Selectivity of the biosensor}

In order to establish the specificity and selectivity of the designed biosensors, different proteins including casein, BSA and cytochrome c were incubated on the biosensor 
surface and DPV measurements were carried out under the same experimental conditions as those described for Lys analysis. As shown in Figure 4, the presence of these proteins exhibited a negligible response compared with that of Lys, even in the case of cytochrome $\mathrm{c}$ which is structurally similar to Lys. Therefore, the results demonstrated that the developed strategy could be used to identify Lys with high specificity.

$<$ Figure 5 $>$

\subsection{Application of the biosensor for the detection of Lys in spiked wine sample}

In order to demonstrate the analytical reliability and applicability of the method for real sample matrix, analysis of wine samples were performed by spiking at three different concentrations of Lys (1.5 nM-5 pM). The recovery values were determined in accordance with the calibration curve performed in buffer. The obtained Lys concentrations were in consistent with the spiked values, indicating the suitability of method for real sample analysis. The recovery results along with other analytical characteristic for the proposed biosensors are presented in the table 2.

$<$ Table 2>

\section{Conclusions}

In conclusion, a novel electrochemical biosensor has been successfully developed for the detection of lysozyme protein based on a hybrid sandwich protocol. Differential Pulse Voltammetry was used to detect Lys via the changes in 1-naphthol oxidation signals. The described biosensor showed a lower detection limit (4.3fM) as compared to the previously reported biosensors for lysozyme detection (Table1), wide linear range for lysozyme detection from $5 \mathrm{fM}$ to $5 \mathrm{nM}$, high sensitivity and selectivity. In addition, the biosensor was used for detecting lysozyme in spiked wine samples and very 
promising recovery values were obtained, indicating the great potential of proposed methodology for detecting lysozyme in wines and possibly other food matrices.

\section{Acknowledgement}

Prof Dr Jean Louis Marty and Dr Alina Vasilescu would like to thanks BRANCUSI Project.

\section{References}

1. T. F. McGrath, J. Buijs, A. C. Huet, P. Delahaut, C. T. Elliott and M. H. Mooney, Sensors and Actuators B: Chemical, 2013, 186, 423-430.

2. P. D'Orazio, Clinica Chimica Acta, 2011, 412, 1749-1761.

3. V. Scognamiglio, F. Arduini, G. Palleschi and G. Rea, TrAC Trends in Analytical Chemistry, 2014, 62, 1-10.

4. G. D. Griffin, D. N. Stratis-Cullum and T. E. McKnight, in Reference Module in Biomedical Sciences, Elsevier, 2014.

5. A. D. Ellington and J. W. Szostak, Nature, 1990, 346, 818-822.

6. $\quad$ E. Luzi, M. Minunni, S. Tombelli and M. Mascini, TrAC Trends in Analytical Chemistry, 2003, 22, 810-818.

7. K. A. Davis, B. Abrams, Y. Lin and S. D. Jayasena, Nucleic Acids Res., 1996, 24, 702-706.

8. S. Tombelli, M. Minunni and M. Mascini, Biomolecular Engineering, 2007, 24, 191-200.

9. A. Hayat, A. Sassolas, J. L. Marty and A. E. Radi, Talanta, 2013, 103, 14-19.

10. L. Zhang, P. Cui, B. Zhang and F. Gao, Chemistry - A European Journal, 2013, 19, 9242-9250.

11. N. J. Ronkainen, H. B. Halsall and W. R. Heineman, Chem. Soc. Rev., 2010, 39, 1747-1763.

12. M. Schindler, Y. Assaf, N. Sharon and D. M. Chipman, Biochemistry, 1977, 16, 423-431.

13. L. E. H. Smith, L. H. Mohr and M. A. Raftery, Journal of the American Chemical Society, 1973, 95, 7497-7500.

14. M. E. Revenis and M. A. Kaliner, The Journal of Pediatrics, 1992, 121, 262270.

15. B. Porstmann, K. Jung, H. Schmechta, U. Evers, M. Pergande, T. Porstmann, H.-J. Kramm and H. Krause, Clinical Biochemistry, 1989, 22, 349-355.

16. R. S. Pascual, J. B. L. Gee and S. C. Finch, New England Journal of Medicine, 1973, 289, 1074-1076.

17. C. Lasanta, A. Roldán, I. Caro, L. Pérez and V. Palacios, Food Control, 2010, 21, 1442-1447.

18. M. Kondeková, V. Maier, P. Ginterová, J. Marák and J. Ševčík, Food Chemistry, 2014, 153, 398-404.

19. C. Chen, X.-M. Sun and B.-H. Li, Chinese Journal of Analytical Chemistry, 2011, 39, 91-94. 
20. R. Chander and N. Lewis, European J. Appl. Microbiol. Biotechnol., 1980, 10, 253-258.

21. I. O. o. V. a. Wine, 2013.

22. A. Vasilescu, S. Gaspar, I. Mihai, A. Tache and S. C. Litescu, Analyst, 2013, 138, 3530-3537.

23. D. T. Tran, K. P. Janssen, J. Pollet, E. Lammertyn, J. Anne, A. Van Schepdael and J. Lammertyn, Molecules (Basel, Switzerland), 2010, 15, 1127-1140.

24. I. Mihai, A. Vezeanu, C. Polonschii, C. Albu, G.-L. Radu and A. Vasilescu, Sensors and Actuators B: Chemical, 2015, 206, 198-204.

25. Y. Li, H. Qi, Q. Gao and C. Zhang, Biosens. Bioelectron., 2011, 26, 2733-2736.

26. H. Wang, W. Gong, Z. Tan, X. Yin and L. Wang, Electrochim. Acta, 2012, 76, 416-423.

27. Y. Xiao, Y. Wang, M. Wu, X. Ma and X. Yang, Journal of Electroanalytical Chemistry, 2013, 702, 49-55.

28. A. Erdem, E. Eksin and M. Muti, Colloids and Surfaces B: Biointerfaces, 2014, 115, 205-211.

29. F. Rohrbach, H. Karadeniz, A. Erdem, M. Famulok and G. Mayer, Anal. Biochem., 2012, 421, 454-459.

30. Y. Peng, D. Zhang, Y. Li, H. Qi, Q. Gao and C. Zhang, Biosens. Bioelectron., 2009, 25, 94-99.

31. Y. Xia, S. Gan, Q. Xu, X. Qiu, P. Gao and S. Huang, Biosens. Bioelectron., 2013, 39, 250-254.

32. M. C. Rodríguez and G. A. Rivas, Talanta, 2009, 78, 212-216.

33. Z. Chen and J. Guo, Electrochim. Acta, 2013, 111, 916-920.

34. D. Xie, C. Li, L. Shangguan, H. Qi, D. Xue, Q. Gao and C. Zhang, Sensors and Actuators B: Chemical, 2014, 192, 558-564.

35. Z. Chen, L. Li, Y. Tian, X. Mu and L. Guo, Biosens. Bioelectron., 2012, 38, $37-$ 42 . 


\section{Figures and Captions}

Figure 1. Schematic representation of the developed sandwich biosensor.

Figure 2. a) Optimization of the concentration ofAbLysantibody. b) Optimization of the concentration ofav-ALP. c) Optimization of incubation time withLys. Uncertainty values corresponding to replicate experiments $(n=3)$.

Figure 3. a) DPV curves for different concentrations of Lys: b) Calibration curve and regression plot of the biosensor. Uncertainty values corresponding to replicate experiments $(n=3)$.

Figure 4 .Selectivity of the biosensor to casein, BSA and cytochrome Cat 5nM, respectively. Error bars are obtained based on three independent measurements. 


\section{Tables}

Table 1. Comparison of the proposed biosensor with other reported methodologies for lysozyme detection.

\begin{tabular}{|c|c|c|c|}
\hline $\begin{array}{l}\text { Analytical } \\
\text { Technique }\end{array}$ & Detection Limit & Linear Range & Reference \\
\hline Electroluminescence & $120 \mathrm{pM}$ & $64 \mathrm{pM}-0.64 \mu \mathrm{M}$ & 25 \\
\hline Electroluminescence & $\begin{array}{l}0.15 \mathrm{ng} \cdot \mathrm{mL}^{-} \\
{ }^{1}(\sim 10.4 \mathrm{pM})\end{array}$ & $0.5 \mathrm{nM}-9 \mathrm{nM}$ & 26 \\
\hline SPR & $2.4 \mathrm{nM}$ & $0.5-80 \mu \mathrm{g} \cdot \mathrm{mL}^{-1}$ & 24 \\
\hline Impedance & $6 \mathrm{fM}$ & $0.01-0.5 \mathrm{pM}$ & 27 \\
\hline Impedance & $28.53 \mathrm{nM}$ & & 28 \\
\hline Impedance & $862 \mathrm{nM}$ & $0-400 \mu \mathrm{g} \cdot \mathrm{mL}^{-1}$ & 29 \\
\hline Impedance & $0.07 \mathrm{nM}$ & $0.2 \mathrm{nM}-4 \mathrm{nM}$ & 30 \\
\hline $\begin{array}{l}\text { Square Wave } \\
\text { Voltammetry }\end{array}$ & $0.2 \mathrm{nM}$ & $0.5 \mathrm{nM}-100 \mathrm{nM}$ & 31 \\
\hline $\begin{array}{l}\text { Square Wave } \\
\text { Voltammetry }\end{array}$ & $38 / 16 \mathrm{nM}$ & $0-30 \mathrm{mg} \cdot \mathrm{L}^{-1}$ & 32 \\
\hline $\begin{array}{l}\text { Square Wave } \\
\text { Voltammetry }\end{array}$ & $1 \mathrm{nM}$ & 7-30nM & 33 \\
\hline $\begin{array}{l}\text { Square Wave } \\
\text { Voltammetry }\end{array}$ & $\begin{array}{l}0.3 \mathrm{pg} \cdot \mathrm{mL}^{-} \\
{ }^{1}(\sim 20.8 \mathrm{fM})\end{array}$ & $1-50 \mathrm{pg} \cdot \mathrm{mL}^{-1}$ & 34 \\
\hline Cyclic Voltammetry & $0.1 \mathrm{pM}$ & $5 \mathrm{pM}-1 \mathrm{nM}$ & 35 \\
\hline $\begin{array}{c}\text { Differential Pulse } \\
\text { Voltammetry }\end{array}$ & $4.3 \mathrm{fM}$ & $5 \mathrm{fM}-5 \mathrm{nM}$ & Our work \\
\hline
\end{tabular}


Table 2. Recovery studies performed in spiked wine samples for applicability of biosensor $(n=3)$.

\begin{tabular}{ccccc}
\hline $\begin{array}{c}\text { Spiked [Lys] } \\
(\mathrm{M})\end{array}$ & $\begin{array}{c}\text { Found [Lys] } \\
(\mathrm{M})\end{array}$ & R.S.D.\% & Recovery \% & Relative error \% \\
& & & & \\
\hline $1.5 .10^{-9}$ & $1.45 .10^{-9}$ & 3.1 & 96.67 & 3.33 \\
$2.5 .10^{-11}$ & $2.38 .10^{-11}$ & 4.2 & 95.2 & 4.8 \\
$5.10^{-12}$ & $5.1 .10^{-12}$ & 5.1 & 102 & 1.96 \\
\hline
\end{tabular}




1
2
3
4
5
6
7
8
9
10
11
12
13
14
15
16
17
18
19
20
21
22
23
24
25
26
27
28
29
30
31
32
33
34
35
36
37
38
39
40
41
42
43
44
45
46
47
48
49
50
51
52
53
54
55
56
57
59
60

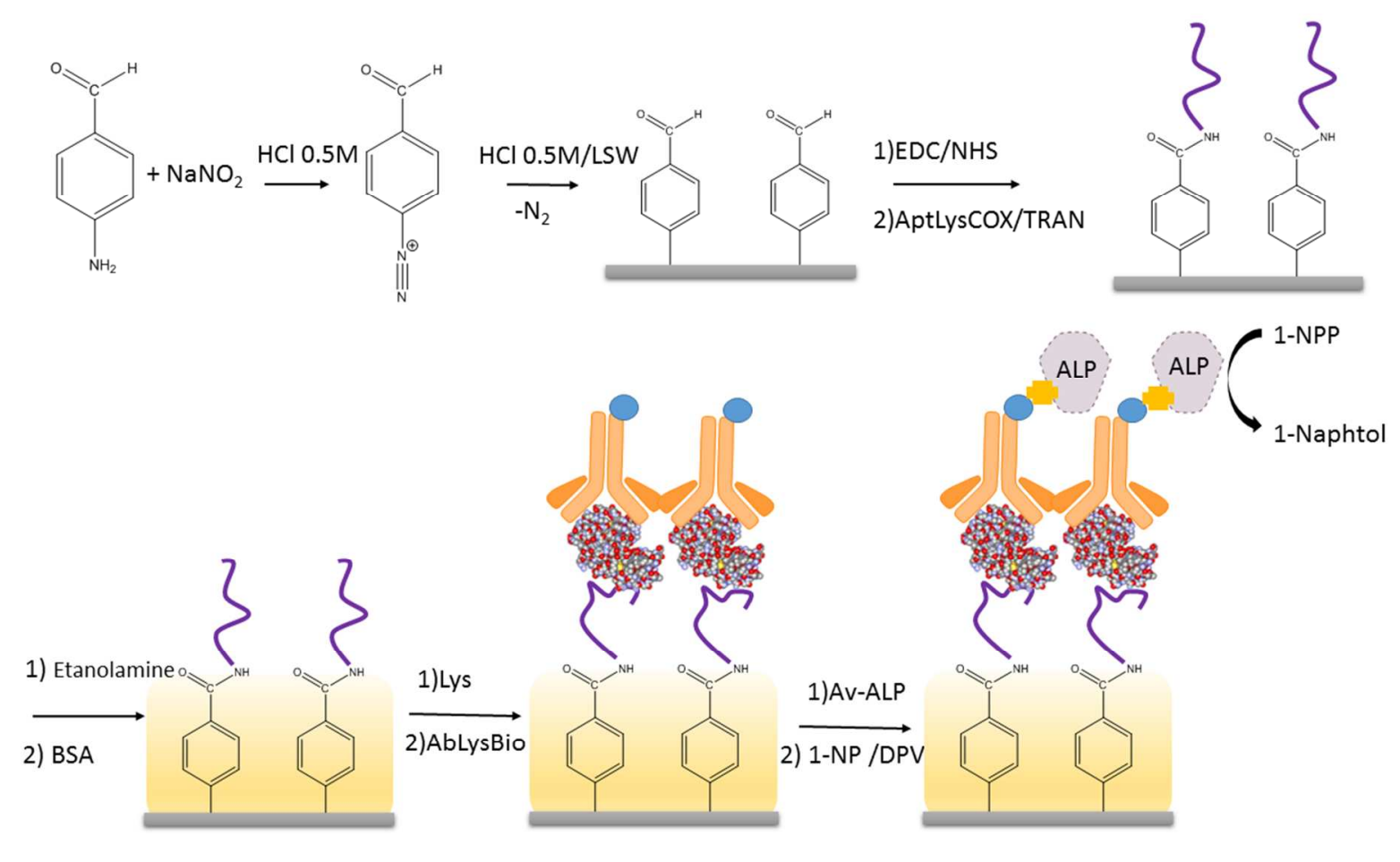

Figure 1 

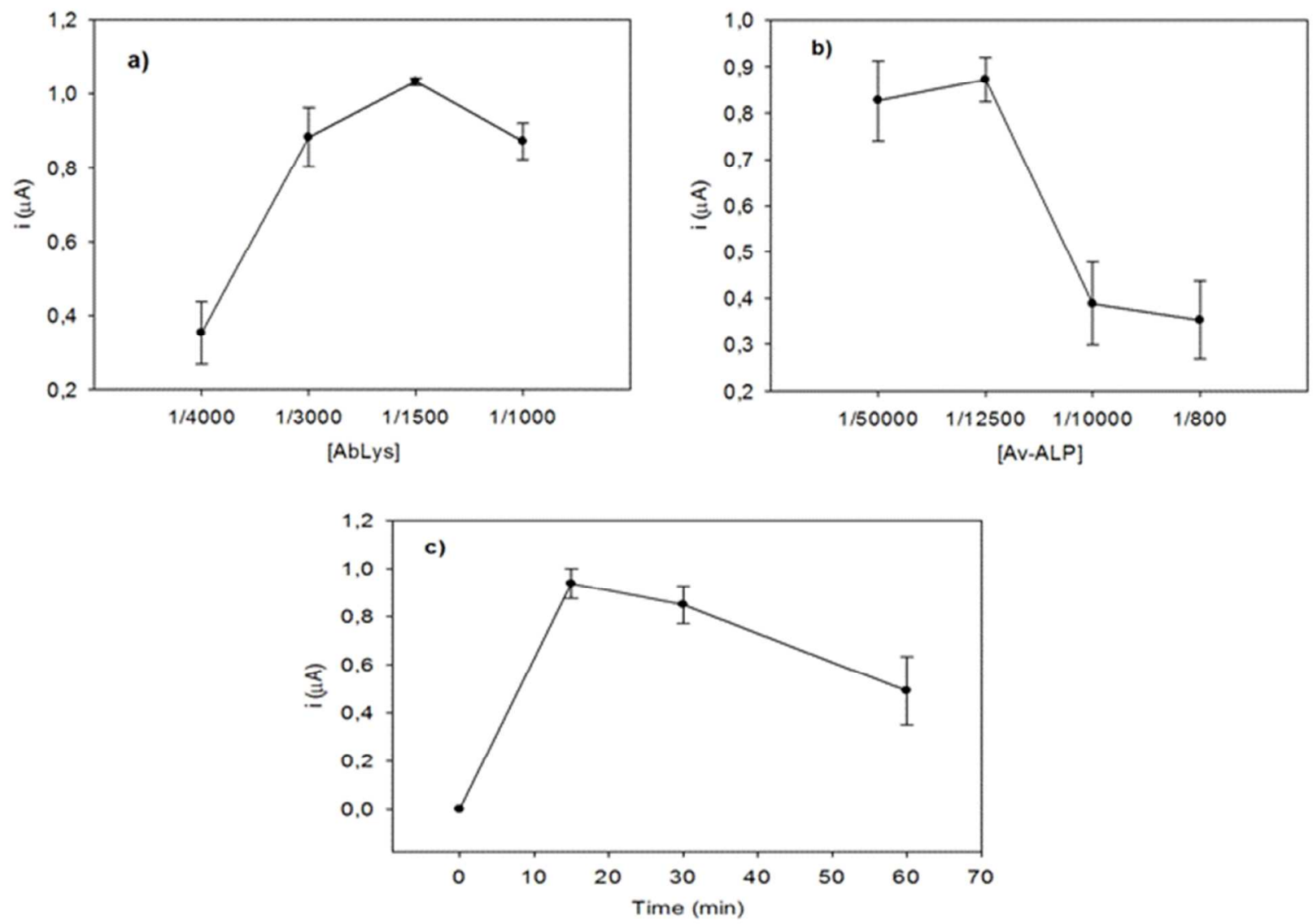

Figure 2 

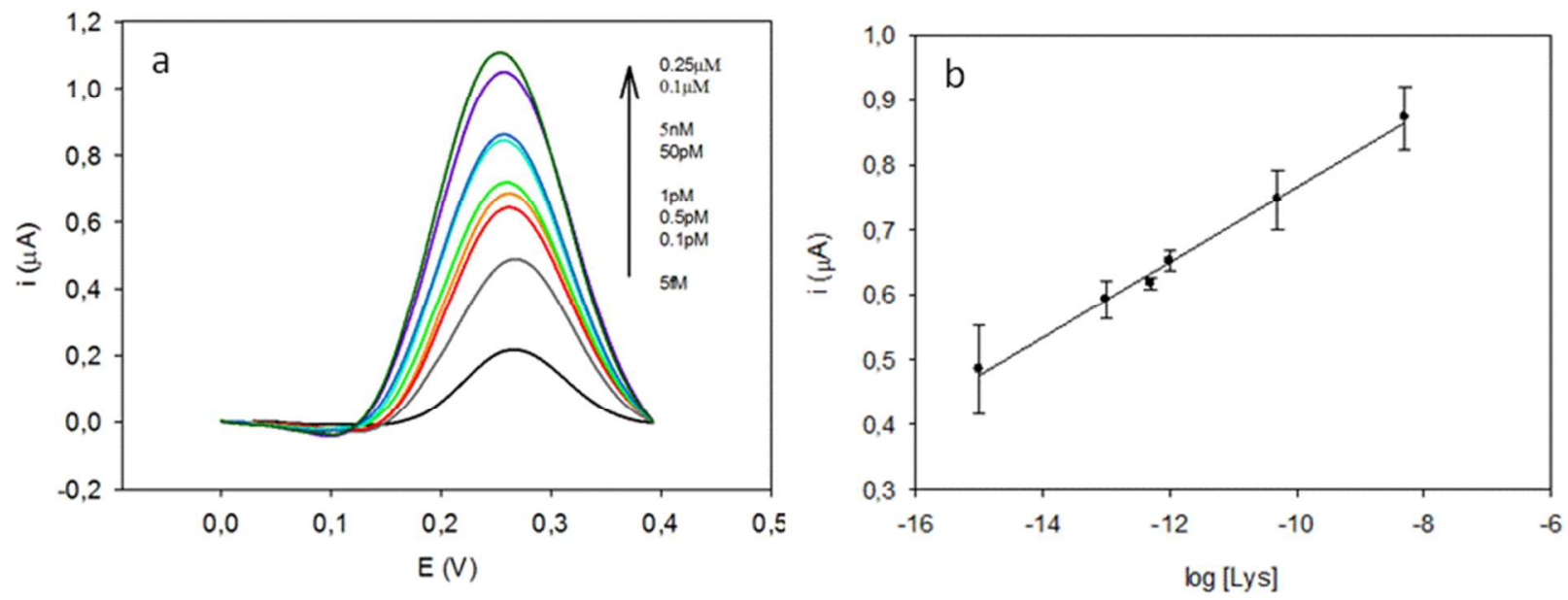

Figure 3

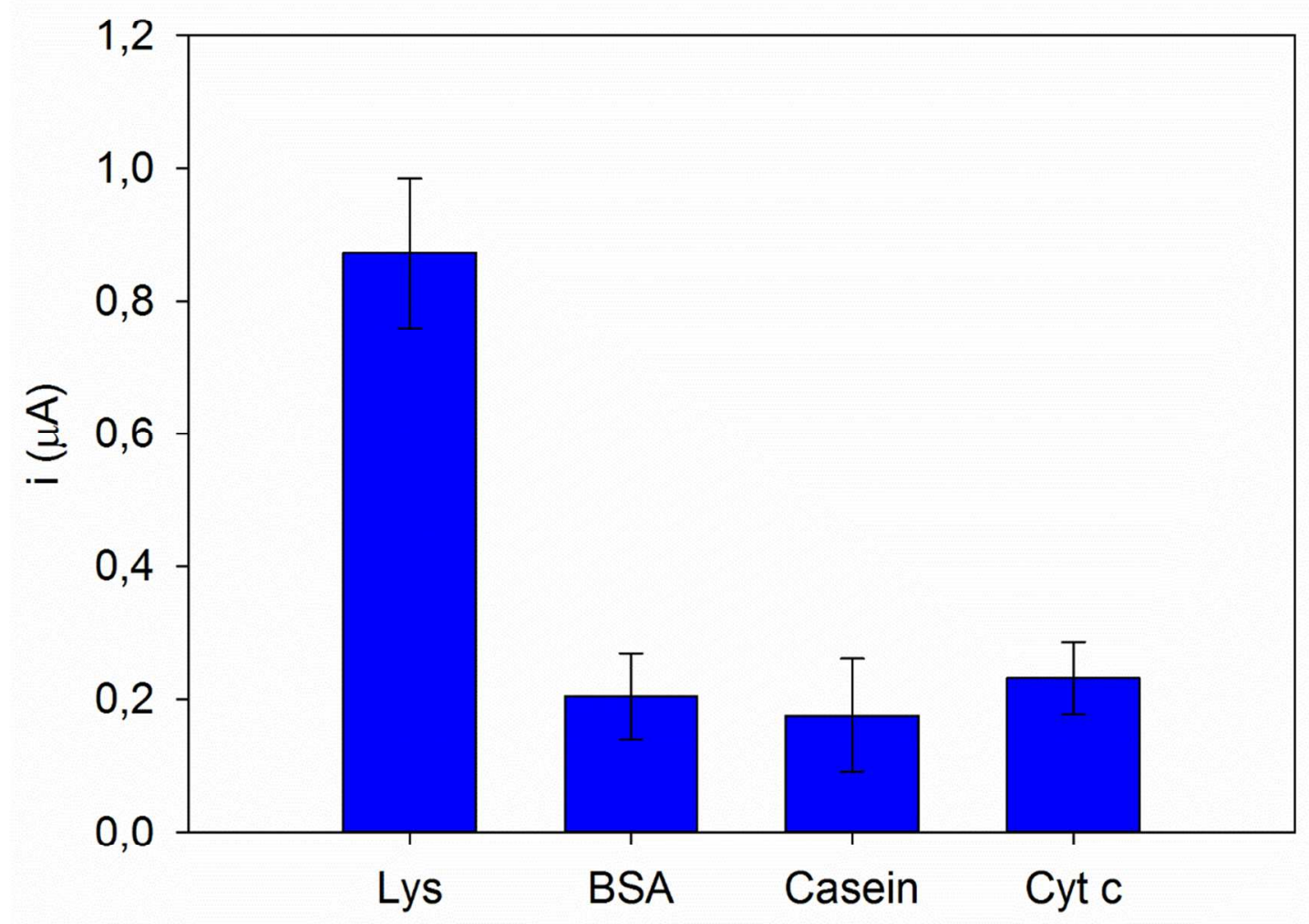

Figure 4 